\title{
Good Day Sunshine: Stock Returns and the Weather*
}

\author{
David Hirshleifer and Tyler Shumway ${ }^{\dagger}$
}

August 17, 2001

*We thank Aldo Rosas for his excellent research assistance. We also thank the editor, Rick Green; an anonymous referee; Andrew Ang, Michael Cooper, Joshua Coval, Bud Gibson, Marc Hulbert, Daniel Kahneman, Seongyeon Lim, Marina Murphy, Norbert Schwarz, Lu Zheng, Jason Zweig, and seminar participants at the Decision Sciences Consortium and at the Mitsui Finance Seminar at the University of Michigan for helpful comments.

${ }^{\dagger}$ Fisher College of Business, Ohio State University; and University of Michigan Business School, respectively. David Hirshleifer can be reached at hirshleifer.2@osu.edu or (614) 292-5174; Fisher College of Business, The Ohio State University, 740A Fisher Hall, 2100 Neil Avenue, Columbus, OH 43210-1144; http://fisher.osu.edu/facultyguide/faculty/hirshleifer/hirshleifer.htm. Tyler Shumway can be contacted at shumway@umich.edu or (734) 763-4129; University of Michigan Business School, 701 Tappan Street, Ann Arbor, MI 48109-1234; http://www.umich.edu/ `shumway. 


\title{
Good Day Sunshine: Stock Returns and the Weather
}

\begin{abstract}
Psychological evidence and casual intuition predict that sunny weather is associated with upbeat mood. This paper examines the relation between morning sunshine at a country's leading stock exchange and market index stock returns that day at 26 stock exchanges internationally from 1982-97. Sunshine is strongly significantly correlated with daily stock returns. After controlling for sunshine, rain and snow are unrelated to returns. There were positive net-of-transaction costs profits to be made from substantial use of weather-based strategies, but the magnitude of the gains was fairly modest. These findings are difficult to reconcile with fully rational price-setting.
\end{abstract}


I need to laugh, and when the sun is out,

I've got something I can laugh about.

I feel good in a special way;

I'm in love and it's a sunny day.

Good Day Sunshine, Good Day Sunshine, Good Day Sunshine

We take a walk, the sun is shining down,

Burns my feet as they touch the ground.

Good Day Sunshine, Good Day Sunshine, Good Day Sunshine

—John Lennon and Paul McCartney, Revolver, 1966.

\section{Introduction}

Sunshine affects mood, as evidenced by song and verse, daily experience, and formal psychological studies. But does sunlight affect the stock market? ${ }^{1}$

The traditional efficient markets view says no, with minor qualifications. If sunlight affects the weather, it can affect agricultural and perhaps other weather-related firms. But in modern economies in which agriculture plays a modest role, it seems unlikely that whether it is cloudy outside the stock exchange today should affect the rational price of the nation's stock market index. (Even in countries where agriculture plays a large role, it is not clear that one day of sunshine versus cloud cover at the stock exchange should be very informative about harvest yield.)

An alternative view is that sunlight affects mood, and that people tend to evaluate future prospects more optimistically when they are in a good mood than when they are in a bad mood. A literature in psychology has found that mood affects judgment and behavior. An important strand of this literature has provided evidence that mood contains valuable information about the environment. The inferences drawn from mood often go astray however;

\footnotetext{
${ }^{1}$ The very metaphors of thought make light a virtue. A good teacher "illuminates the subject", a smart person is "bright" or "brilliant," a fool is "dim-witted", a superb performer is a "star,", someone who is triumphant "glows with pride," a joyous bride is "radiant," if your "chances are dim" it is time to quit, it is "better to light a fire than curse the darkness," the "dark side of the force" is the evil side, and when we "look at the bright side" we are cheerful. Everyone wants a chance to "shine," just as Germany wanted its "place in the sun." To have even "one brief shining moment" is a glorious thing. The "dawn of a new era" is the start of a magnificent time, and the "twilight of the gods" is death.
} 
people often attribute their mood to the wrong feature of the environment. For example, someone who is in a good mood because of sunshine may unconsciously attribute this feeling to generally favorable life prospects. If such misattribution extends to investments, then stock prices will fluctuate in response to the mood of investors. This suggests that on dim, dull, dreary, depressing days stocks will decline, whereas cheery bright days will boost stocks. The psychological literature on sunlight, mood, and misattribution of mood is discussed in the next section.

For three reasons, examining the effects of sunlight on the stock market provides an attractive means of testing whether psychological biases can affect stock returns. First, any such relation is not subject to the criticism of datasnooping. Exploration of whether this pattern exists was specifically stimulated by the psychological hypothesis - the hypothesis was not selected to match a known pattern. Second, such a pattern, if it exists, has a psychological explanation but no plausible rational explanation. This contrasts with many well-known patterns of stock returns for which psychological and rational explanations are currently competing. Third, sunshine is an easily-measured exogenous influence. ${ }^{2}$ Some previous work emphasizes the dynamics of the social transmission of popular attitudes and theories (see, e.g., Shiller (1984, 2000a)). Some empirical headway along these lines has been made through survey methods (see, e.g., Shiller (1990, 2000b), Hong, Kubik, and Stein (2001)). Here we sidestep the complexities of social learning by focusing on an exogenous external influence.

The first test of the hypothesis that sunshine affects returns involves examining individually for each city the relation between daily cloudiness and daily nominal return on the nation's stock index using univariate regression at 26 stock exchanges internationally from 1982-97. In order to esnure that the effects we identify do not derive from well-known seasonal stock return effects, we examine the deviation between the day's cloudiness and the ordinary expected degree of cloudiness for that day of the year. The analysis does not precldue We examine the relation of cloudiness both to continuous returns, and (in logit regressions) to the probability that the return will be positive. Depending on the specifi-

\footnotetext{
${ }^{2}$ As Roll (1992) put it, "Weather is a genuinely exogenous economic factor. ... It was a favourite example of an exogenous identifying variable in the early econometrics literature... Because weather is both exogenous and unambiguously observable ... weather data should be useful in assessing the information processing ability of financial markets."
} 
cation, in either 18 or 25 of the 26 cities, the relation between returns and cloudiness is negative (in most cases not significantly). Based on a simple non-parametric joint test, it is unlikely that these results would arise by sheer chance.

These city-by-city results strongly suggest that there is a genuine relation between stock returns and cloudiness. To examine this issue in a more structured way, we provide parametric joint (cross-city) tests using the entire data set. We report the results of several such joint tests. In pooled regressions where the intercept and slope are constrained to be the same across cities, we find a highly statistically significant relation between cloud cover and returns $(\mathrm{t}=-4.49)$, or $($ chi-square $=43.6)$ for the logit. However, these tests assume independent errors, which is implausible.

To address this issue, we estimate a city-specific fixed effects model with panel corrected standard errors (PCSE). Our PCSE specification allows errors to be contemporaneously correlated, heteroskedastic across cities and autocorrelated within each city's time series. Once again there is a highly significant negative relation between cloud cover and returns (asymptotic z-statistic $=-3.96$ ). To examine the relation of weather to the probability of a positive return, we estimate a fixed effects linear probability model with PCSE using an indicator variable that is one when returns are positive. This again yields a strongly significant relation $(\mathrm{t}=-6.07)$. In all cases, adjusting for contemporaneous correlation and heteroskedasticity across panels and autocorrelation within panels has little effect on the inference.

The magnitude of the sunshine effect is substantial. For example, in New York City, the annualized nominal market return on perfectly sunny days is approximately $24.8 \%$ per year versus $8.7 \%$ per year on perfectly cloudy days. However, from a trader's perspective, the value of these return differentials depends on whether it is possible to diversify the risk of a sunshine-based trading strategy. We find that for reasonable levels of transactions costs, trading strategies based on the weather generate statistically significant but economically fairly modest improvements in portfolio Sharpe ratios. The set of investors who could potentially have exploited such strategies includes just about everyone: institutional traders and wealthy individuals who are able to conveniently trade index futures; and small investors 
who hold open-end mutual funds. ${ }^{3,4}$

In addition to exploring the feasibility of trading on the sunshine effect, we perform multiple regressions to see whether the results are actually driven by sunshine, or by other associated weather conditions such as rain and snow. We find that sunshine remains significant, and that after controlling for sunshine, rain and snow are essentially unrelated to returns.

The remainder of the paper is structured as follows. Section I discusses psychology, sunshine and stock returns. Section II describes the data we use for our analyses, while Section III reports our evidence in detail. Section IV concludes.

\section{Misattribution of Mood, Sunshine and Stock Re- turns}

A literature in psychology considers how emotions and moods affect human behavior. People who are in good moods make more optimistic choices and judgments than people in bad moods (see Wright and Bower (1992)). Moods most strongly affects relatively abstract judgments about which people lack concrete information (Clore, Schwarz, and Conway (1994), Forgas (1995)). Bad moods tend to stimulate people to engage in detailed analytical activity, whereas good moods are associated with heuristic and less critical modes of information processing (Schwarz (1990); see also Petty, Gleicher, and Baker (1991)). People in good moods are more receptive to weak as well as strong arguments (see Mackie and Worth (1991)). However, people in good moods tend to generate more unusual associations and perform better in creative problem-solving tasks (see the review of Schwarz and Bless (1991)).

Loewenstein (2000) discusses the role of emotions in economic behavior. Particularly relevant for stock market decisions is the finding that mood has strong effects on judgments

\footnotetext{
${ }^{3}$ Boudoukh, Richardson, Subrahmanyam, and Whitelaw (2000) describe how individuals can trade between international stock indices and money marke in open-end mutual fund families at essentially zero cost. However, an important, standard caveat applies. An investor at the start of this time period who did not possess the statistical information possessed by researchers ex post may have had less reason to believe in the profitability of a sunshine-based strategy.

${ }^{4}$ Our findings do not rule out the possibility that weekly or more complex weather-based strategies can retain high returns while further economizing on transaction costs; no doubt practitioners will explore these possibilities.
} 
of risk (Johnson and Tversky (1983)). This is probably related to the fact that judgments and decisions about risk are influenced by feelings and emotional reactions; Loewenstein, Weber, Hsee, and Welch (2001) provide an insightful discussion and review.

An important part of many theories of affective states (emotions or moods) is that such states provide information, perhaps unconsciously, to individuals about the environment (see, e.g., Frijda (1988), Schwarz (1990)). ${ }^{5}$ A substantial body of evidence supports an informational role of affect (see Clore and Parrott (1991), Clore, Schwarz, and Conway (1994), Schwarz (1990), Wilson and Schooler (1991)).

An important finding of this literature is that people often attribute their feelings to the wrong source, leading to incorrect judgments. As an example of this problem of misattribution, people feel happier on sunny days than on rainy days. The effect of sunlight on their judgments about happiness is reduced if they are primed by asking them about the weather (Schwarz and Clore (1983)). Presumably this reminds them to attribute their good mood to sunshine rather than to long-term considerations.

Psychologists have been documenting correlations between sunshine and behavior for decades. Among other things, sunshine (or lack of sunshine) has been linked to depression (Eagles (1994)), suicide (Tietjen and Kripke (1994)) and tipping (Rind (1996)). Most of the psychological evidence suggests that people feel better when they are exposed to more sunshine. If people are more optimistic when the sun shines, they may be more inclined to buy stocks on sunny days. Specifically, they may incorrectly attribute their good mood to positive economic prospects rather than good weather. This suggests that sunshine is positively correlated with stock returns. Furthermore, the prediction is not that the news (as in a weather forecast) that the day will be sunny causes an immediate and complete positive stock price reaction. Rather, it is the occurence of the sunshine itself that should cause prices to move.

An alternative to the informational perspective on affect is to view feelings as affecting preferences. Loewenstein (1996) reviews literature on, and models how, 'visceral factors' such as hunger, fatigue, sexual desire, moods, emotions, pain and drug cravings affect

\footnotetext{
${ }^{5}$ Consistent with this view, people often talk approvingly about making decisions based on 'gut feelings,' good or bad 'vibes,' or doing 'what your heart tells you.' However, ordinary conversation also includes criticism of bad judgments based on feelings ("Marry in haste, repent at leisure.").
} 
preferences between different goods. Mehra and Sah (2000) provide an analysis of the determination of stock prices when mood affects preferences. They show that small random fluctations in preference parameters can cause signficant volatility in prices.

In contrast, if people are rational maximizers, there is little reason to conjecture that sunshine is correlated with stock returns. It is certainly likely that weather affects economic output, particularly in industries like agriculture and construction. However, the sunshine that occurs in one particular location is not generally representative of the weather in an entire economy. Moreover, sunshine is a transitory variable. The amount of unexpected sunshine occuring today is not highly correlated with the amount that will prevail one week or one month from today. Finally, rain or snowfall should be more strongly correlated with output than sunshine. In fact, strong storms might hamper markets or make information generation temporarily less available. We test for rain and snowfall effects, separating any rain and snowfall effects we find from the sunshine effect. ${ }^{6}$

There is already some evidence that sunshine influences markets. Saunders (1993) shows that when it is cloudy in New York City, New York Stock Exchange index returns tend to be negative. He shows that the cloudiness/returns correlation is robust to various choices of stock index and regression specification. Although this finding is noteworthy, it has received little attention, possibly because of concerns about unintentional datamining. Studies that identify significant relationships are more likely to be published than those that find nothing, so there will always be well-executed, published papers describing significant, but meaningless results. Our paper helps remedy this potential concern with respect to sunshine effects by examining data from many exchanges.

Kamstra, Kramer, and Levi (2000a) use data from several countries to show that the Friday-Monday return is significantly lower on daylight-savings weekends than on other weekends. However, such changes can affect sleep patterns, not just waking hours of sunlight. Furthermore, examining weather data allows us to exploit the full sample of daily returns instead of a sample restricted to the dates of daylight savings changes.

Kamstra, Kramer, and Levi (2000b) examines the effects of seasonal shifts in length of

\footnotetext{
${ }^{6}$ If people derive utility from both consumption and sunshine, some correlation between stock returns and sunshine will be induced. However, most rational models do not attempt to capture stocks' sunshine risk.
} 
day in 5 stock markets (including markets in both the Northern and Southern hemisphere). They find that stock market returns are significantly related to season, and argue that this relation arises because of the deterministic shifts in the length of day through the seasons. They therefore suggest that deterministic variations in length of day helps explain the January effect. ${ }^{7}$

We examine here the relation of stock returns to a stochastic variable, the realization of the weather. We test the hypothesis that cloudy weather is correlated with poor stock returns. We do this with a sample of 26 stock exchanges. Using a panel rather than a long time series has three advantages.

First, it helps identify whether the hypothesized phenomenon is pervasive. The psychological argument for the effect of sunshine should apply globally.

Second, our recent sample allows us to examine whether this phenomenon is still present in the years subsequent to Saunders (1993). If financial markets have become more efficient over time, it is possible that the sunshine effect found by Saunders is no longer relevant. Consistent with this notion, Saunders found that his regression does not work well in the last subperiod of his sample (1983-1989). However, our study finds that sunshine effects are still present internationally and in the U.S..

Third, the panel increases our power to detect an effect. Even if sunshine affects returns, we know there are many other important influences on any given day. Most variation in returns will be driven by economic events and news. Given the high variability of returns, it is useful to maximize power by using a large number of markets.

\section{Data}

Since we want to examine whether stock returns are correlated with cloudiness, we need both stock return and weather data. We collect weather data from the International Surface Weather Observations (ISWO) dataset sold by the National Climactic Data Center (www.ncdc.noaa.gov). The ISWO dataset contains detailed descriptions of the weather at

\footnotetext{
${ }^{7}$ Kramer (2000) examines another possible effect of mood on stock prices. There is evidence of predictable swings in mood over the course of the day. In a meta-analysis of three previous empirical studies on intraday returns, Kramer describes evidence that intraday patterns in expected stock returns are consistent with psychological patterns of diurnal mood swings.
} 
3000 locations worldwide from 1982 to 1997. In most ISWO locations, observations about the wind, cloud cover, and barometric pressure are collected hourly. Since the hypothesis that we examine relates stock returns to the amount of sunshine on a particular day, we collect the ISWO variable that measures total sky cover (SKC). SKC ranges from 0 (clear) to 8 (overcast). We calculate the average cloud cover for each day from 6 a.m. to 4 p.m. local time for cities with stock exchanges. While the ISWO data appear to be of very high quality, a complete record of sky cover observations is not available for all of the cities with major stock exchanges. In particular, SKC data for Tokyo, Hong Kong, Seoul, Lisbon, Mexico City, Toronto, Jakarta, Frankfurt, and Wellington are not sufficiently complete to make data from these cities usable.

Of course, the daily cloud cover in any particular city is highly seasonal. For example, winter months are associated with cloudier weather in New York City. Many seasonal patterns have been identified in stock return data as well (e.g. Keim (1983)), and numerous possible causal forces exhibit annual seasonality. To be certain that our results are driven by cloudiness rather than other seasonal effects, we therefore deseasonalize the cloud data. This provides a conservative measure of the effect of cloud cover, in the sense that we exclude any contribution that cloud cover may make to seasonal return patterns.

We calculate the average cloudiness value for each week of the year in each city, and deseasonalize by subtracting each week's mean cloudiness from each daily mean. For example, we calculate the average value of $\mathrm{SKC}_{i, t}$ for the first full calendar week of the year for a particular city, taking an average of 80 values (16 years times 5 days in the week). Then we subtract this mean from the city's daily $\mathrm{SKC}_{i, t}$ values in the first week of each year. We denote the deseasonalized value of SKC for city $i$ on day $t$ as $\mathrm{SKC}_{i t}^{*}$. The mean of $\mathrm{SKC}_{i t}^{*}$ is close to zero, and its global standard deviation is 2.19 .

In order to check whether our results are driven by adverse weather conditions, we include measures of raininess and snowiness in some of our regression specifications. The ISWO dataset contains a number of variables that describe the current and recently passed weather at each station. We use these variables to determine whether it is raining or has rained within the last observation period at each station. We then average the number of observation periods for which rain is reported per day. We perform similar calculations for snowy weather. Finally, we deseasonalize our raininess and snowiness variables by week 
in the same way that we deseasonalize the SKC variable. We denote the deseasonalized raininess in location $i$ on day $t \mathrm{RAIN}_{i t}^{*}$ and we denote our deseasonalized snow variable $\mathrm{SNOW}_{i t}^{*}$.

We collect daily index returns from Datastream. All cities that have data from at least 1988 to 1997 are included in the analysis. For most cities, we use the market index calculated by Datastream (Datastream Global Index). However, for several cities, other indices exist with longer time series. Thus, we collect the following indices for the corresponding locations: Bovespa for Rio de Janeiro, IGPA for Santiago, Hex for Helsinki, Kuala Lumpur Composite for Kuala Lumpur, PSE Composite for Manila, Madrid SE General for Madrid, Taiwan SE Weighted for Taipei, and the Bangkok Composite for Bangkok.

Some summary statistics for the sample appear in Table I. The cloudiness measure used to calculate the means in Table I is the original $\mathrm{SKC}_{i t}$, complete with its seasonal variability. It is evident from the sample statistics that some cities consistently experience more sunshine than other cities. Moreover, some cities appear to have substantially higher expected returns than other cities. This can be understood by noting that all returns are nominal returns expressed in local currencies. Some currencies, like that of Brazil, experience substantial inflation, so high nominal returns are not surprising.

A correlation matrix of both deseasonalized cloudiness, $\mathrm{SKC}_{i t}^{*}$, and of daily returns appears in Table II. The cross-city correlations of returns appear below the diagonal in the table, while the cloudiness correlations are above the diagonal. While no measure of statistical significance is reported in the table, almost all correlations greater in absolute value that 0.04 are significant at the five percent level. Not surprisingly, most of the returns correlations are positive, large, and significant. Only two estimated correlations are negative, and none are larger than 0.65. Thus, while the global component of daily international returns is fairly large, there is also a large local component to each national index returns. We expect that cloudiness affects the local component of an index return.

Even after deseasonalizing cloudiness, there are many significant cross-city correlations. The cloudiness correlations appear to be determined largely by geography, with proximate cities exhibiting large correlations. The correlations in returns and cloudiness present econometric problems that our test specifications will have to overcome. 


\section{Evidence}

This section describes the statistical results of testing the hypothesis that cloudy weather is associated with low stock market returns. Our first set of results concerns some very simple specifications estimated city-by-city. Simple city-by-city specifications give us an idea of the significance of cloudiness in explaining returns. However, given the relatively short time series in our sample, we cannot expect many individual city results to be statistically significant.

Because there is a tremendous amount of variation in individual index stock returns, to increase power we perform joint tests that employ the entire panel of 26 exchanges. We also check whether raininess or snowiness are correlated with returns, and whether any correlation between sunshine and returns can be explained by raininess and snowiness. Finally, we examine the economic significance of the sunshine effect with traditional measures similar to $\mathrm{R}^{2}$ and with a simple trading strategy.

\section{A. City-by-City Tests}

We first estimate simple regressions that are similar to those in Saunders (1993). Specifically, we estimate the parameters of the regression equation,

$$
r_{i t}=\alpha_{i}+\beta_{i C} \mathrm{SKC}_{i t}^{*}+e_{i t}
$$

Ordinary least squares estimates of the $\beta_{i C}$ coefficient of this regression are reported in the third column of Table III, and the associated $t$-statistics are reported in the fourth column of Table III. The results are quite robust. Estimates that use the original cloudiness measure $\left(\mathrm{SKC}_{i t}\right)$ are quite similar to those reported. Regressions that replace the cloudiness measure with a variable that is set to one when $\mathrm{SKC}_{i t}$ is less than one, to zero when $\mathrm{SKC}_{i t}$ is between one and seven, and to minus one when $\mathrm{SKC}_{i t}$ is greater than seven, also produce very similar results.

It might be conjectured that it is not just cloudiness per se, but also the change in cloudiness from the previous day that influences moods. While regressions of returns on changes in cloudiness produce results that are similar to the levels results in Table III, the levels results are slightly stronger so we do not report the changes results. When both levels 
and changes are included in the regression, the levels remain significant but the changes coefficient becomes insignificant.

The simple regression coefficients in Table III already give an idea of the global significance of cloudiness for returns. Four of the negative estimated coefficients are significantly different from zero using a two-tailed, five percent test. However, Saunders (1993) argues that a one-tailed test is appropriate, since the alternative hypothesis being examined concerns only the left tail. Using a one-tailed, five percent test, seven of the 26 coefficients are statistically significantly negative. In contrast, the largest positive $t$-statistic is 0.83 .

We can examine the joint significance of these results with some simple nonparametric calculations. The coefficient on $\mathrm{SKC}_{i t}^{*}$ is positive for 8 out of 26 cities. If the sign of each regression is an independent draw from the binomial distribution, and if the probability of drawing a negative coefficient is 0.5 , then the probability of finding only 8 positive coefficients out of 26 possible is 0.038 . This is within the $5 \%$ level of significance for a one-tailed test. The simple regression coefficients reported in Table III suggest that cloudiness and returns are correlated.

However, the simple regressions may not be the most powerful way to examine our hypothesis. The simple regressions relate the level of returns on any given day to the percentage of cloud cover on that particular day. Thus, while a fairly cloudy day $\left(\mathrm{SKC}_{i t}=6\right)$ may be associated with negative index returns, a very cloudy day $\left(\mathrm{SKC}_{i t}=8\right)$ should be associated with very negative returns according to the simple regression. Saunders (1993) finds that returns are negative more often on cloudy days than on sunny days. It is possible that while the sign of an index return on a particular day is related to the exchange city's cloudiness that day, the magnitude of the index return is not strongly related to cloudiness.

To examine this alternative specification, we estimate logit models of the form

$$
P\left(r_{i t}>0\right)=\frac{e^{\gamma_{i C} \mathrm{SKC}_{i t}^{*}}}{1+e^{\gamma_{i C} \mathrm{SKC}_{i t}^{*}}}
$$

by maximum likelihood. The fifth column of Table III reports the estimates of $\gamma_{i C}$. The sixth and seventh columns of Table III report each coefficient's chi-square test of statistical significance and its associated P-value.

While only four of the simple regression coefficients are statistically significant in the five percent, two-tailed test, five of the logit coefficients are significant at this level. Furthermore, 
nine of the coefficients are significant at the ten percent level, or equivalently, in a one-tailed test. Again, no positive estimate of $\gamma_{i C}$ is even close to significant.

In fact, 25 out of 26 estimated $\gamma_{i C}$ coefficients are negative. Performing the same calculation as before, if each of the signs of the $\gamma_{i C}$ was independently binomial $(p=0.5)$, the probability of this occuring would be $4 \times 10^{-7}$. This is quite strong evidence that cloudiness is correlated with returns.

Moreover, the chi-share test statistic for the New York logit regression is highly statistically significant, with an associated P-value of 0.0033 . This is remarkable because Saunders (1993) finds that the sunshine effect is insignificant in the last subperiod of his sample (1983-1989). Saunders concludes that the sunshine effect may be of purely historical interest. Splitting the New York logit regression into similar subperiods, the logit coefficient estimate calculated with our data for the eight-year period from 1982 to 1989 is -0.0136 with an associated chi-square statistic of $0.68(\mathrm{P}$-value $=0.4081)$. However, the logit coefficient estimate for the eight-year period from 1990 to 1997 is -0.0578 with an associated chi-square statistic of 11.38 (P-value $=0.0007)$. Thus, although we replicate Saunders' finding that the weather effect was weak in the 1980's, the sunshine effect appears most strongly in New York during the 90's. Because of sampling noise, eight years is a short period of time to measure these effects, so the results are consistent with a stable sunshine effect through the entire period.

\section{B. Joint Tests}

While the city-by-city results reported above strongly suggest that stock returns are correlated with cloudiness, we can use the entire data set to make more definitive statements about the statistical significance of the cloudiness effect. We report the results of several joint (across cities/indices) tests of significance in this section.

The first joint tests can be considered simple generalizations of the regressions described above. We estimate one regression with the simple specification of equation (1) with all of the data from each city. We refer to this as a pooled regression. In particular, we estimate a pooled regression of the form

$$
r_{i t}=\alpha+\beta_{C} \mathrm{SKC}_{i t}^{*}+e_{i t}
$$


where now the parameters $\alpha$ and $\beta_{C}$ are constrained to be the same across markets. In this simple pooled specification, we assume that the error terms, $e_{i t}$, are identically and independently distributed (iid). This specification does not adjust for any contemporaneous correlations across the error terms of different indices, nor does it adjust for any autocorrelation among a particular index's errors. Contemporaneous correlation across index-specific error terms almost certainly exists, given the correlations in Table II.

The results of the simple pooled regression appear in the penultimate line of Table III. The $\beta_{C}$ coefficient estimate is -0.011 , which is approximately the mean of the city-by-city estimates. The associated $t$-statistic is -4.49 , which is highly statistically significant.

We also perform a pooled test with the logit model described by equation (2). Again, we simply concatenate the data from each city, resulting in one sample of 92,808 observations, $53.2 \%$ of which are positive. The estimate of $\gamma_{c}$ is -0.02 , approximately the mean of the city-by-city results. Moreover, the chi-square test of statistical significance is 43.6, which is very statistically significant. However, these test statistics are also based on the dubious assumption that each observation is iid.

To allow for violations of the assumption that each error term is iid, we estimate a city-specific fixed effects model of the form

$$
r_{i t}=\alpha_{i}+\beta_{C} \mathrm{SKC}_{i t}^{*}+e_{i t}
$$

with panel corrected standard errors (PCSE). Our PCSE specification allows $e_{i t}$ to be contemporaneously correlated and heteroskedastic across cities, and autocorrelated within each city's time series. We estimate $\beta_{C}$ to be -0.010 with an associated asymptotic z-statistic of -3.96. These estimates are quite close to the naive pooled estimates discussed above, so adjusting for the correlations in the panel data does not reduce the power of the inference very much.

Adjusting the logit model for panel correlations is significantly more complicated than adjusting the simple regression. Therefore, we estimate a fixed effects linear probability model with PCSE of the form,

$$
I\left(r_{i t}>0\right)=\alpha_{P, i}+\beta_{P} \mathrm{SKC}_{i t}^{*}+e_{i t}
$$

where $I\left(r_{i t}>0\right)$ is an indicator variable that is one when returns are positive. Estimating this regression yields an estimate of $\beta_{P}$ of -0.005 with an associated $t$-statistic of -6.07 . 
Again, adjusting for contemporaneous correlation and heteroskedasticity across panels and autocorrelation within panels has little effect on the inference.

The sunshine effect has been criticized by Trombley (1997) on the grounds that the results documented for New York weather and returns in Saunders (1993) are not statistically significant in each month of the year and subperiod of the data (a criterion which we regard as unduly strict). Trombley also finds that average returns do not appear to be a monotonic function of cloudiness in Saunders' data. In unreported tests that employ our entire panel of data, we find that average returns are almost monotonically decreasing in cloudiness and that the effect of cloudiness on returns is negative in all twelve months of the year and significantly negative in one-sided tests in six of the twelve months. Overall, our finding that sunshine is statistically significantly correlated with daily returns appears quite robust.

\section{Controlling for Adverse Weather}

As discussed above, it is possible that sunshine is just a proxy variable for other weather conditions such as lack of rain or snow, that may be correlated with stock returns. We examine this hypothesis by measuring raininess and snowiness and including adverse weather conditions in the regressions. The regressions that we estimate and report in Table IV take the form

$$
r_{i t}=\alpha_{i}+\beta_{i C} \mathrm{SKC}_{i t}^{*}+\beta_{i R} \mathrm{RAIN}_{i t}^{*}+\beta_{i S} \mathrm{SNOW}_{i t}^{*}+e_{i t},
$$

where the variables are measured as defined in Section II. Table V reports estimates of logit models analogous to those described in the previous subsection.

The results in Tables IV and V indicate that the sunshine effect is not explained by other weather conditions. In Table IV, only nine of the 26 sky cover coefficients are positive. In the regressions without raininess and snowiness (in Table III), eight of the coefficients are positive. Similar to the regressions without raininess and snowiness, three of the coefficients are significantly negative at the five percent level, but none of the coefficients is close to significantly positive. By comparison, raininess and snowiness have 12 and 13 positive estimated coefficients respectively. Two of the raininess and one of the snowiness coefficients are statistically significant. 
While the city-by-city results in Table IV suggest that the sunshine effect is independent of raininess and snowiness, we can design more powerful tests of the adverse weather explanation by considering all cities' returns jointly. The last two lines of Table IV report the results of a pooled regression and a fixed-effects PCSE regression analogous to those regressions described in the previous subsection. In both regressions, the coefficient on sky cover is significantly negative, with $t$-statistics of -3.94 and -3.47 . However, raininess and snowiness are economically and statistically insignificant in both specifications. Overall, the results of Table IV do not support the other-weather-condition explanation of our results.

The binary results in Table $\mathrm{V}$ are not favorable to the adverse weather hypothesis either. As in the previous section, the logit model estimates reported in Table $\mathrm{V}$ relate the sign of the return in city $i$ on day $t$ to the weather in that city on that day. Specifically, the models we estimate are of the form

$$
P\left(r_{i t}>0\right)=\frac{e^{\gamma_{i C} \mathrm{SKC}_{i t}^{*}+\gamma_{i R} \mathrm{RAIN}_{i t}^{*}+\gamma_{i S} \mathrm{SNOW}_{i t}^{*}}}{1+e^{\gamma_{i C} \mathrm{SKC}_{i t}^{*}+\gamma_{i R} \mathrm{RAIN}_{i t}^{*}+\gamma_{i S} \mathrm{SNOW}_{i t}^{*}} .}
$$

Looking at the city-by-city results, only four of the sky cover coefficient estimates are positive, while four of the estimates are significantly negative. While four of the raininess coefficients are significantly negative, twelve of the raininess coefficients are positive. None of the snowiness coefficients is significant, and 16 of them are positive. The city-by-city logit results confirm that sunny days tend to coincide with positive returns.

To assess the joint significance of the city-by-city logit estimates, we again estimate a naive pooled logit model and a fixed-effects PCSE linear probability model. The results of the pooled logit model appear in the final row of Table V. The pooled estimate of the logit coefficient on sky cover is -0.017 , which is close to the mean of the city-by-city estimates. The associated chi-square statistics is 28.9 , which indicates that the coefficient estimate is very statistically significant. The coefficient estimate for raininess is -0.190 , and it is statistically significant. The estimate for snowiness is positive and insignificant.

As in the case without adverse weather controls, the fixed-effects PCSE linear probability model is consistent with the pooled logit model. The coefficient estimate for $\mathrm{SKC}_{i, t}^{*}$ is -0.0043 , with an asymptotic Z-statistic of -5.01 . The coefficient estimate for $\mathrm{RAIN}_{i, t}^{*}$ is -0.049 , with a Z-statistic of -3.06 , and the coefficient estimate for $\mathrm{SNOW}_{i, t}^{*}$ is positive and insignificant. Again, even after controlling for other weather conditions, sunshine is strongly 
significantly correlated with both the sign and the magnitude of returns.

\section{Ability of Sunlight to Predict Returns}

With the parameter estimates reported in Table III, we now consider the profitability of trading strategies based upon the sunshine effect, and whether morning sunlight can predict returns for the day. We use the coefficient of the simple pooled regression, -0.011 , as our estimate of the sunshine effect. The mean daily return across all countries is 0.103 , with a standard deviation of 1.58. We know that the cloudiness variable ranges from zero to eight, so the difference in expected return between a completely overcast day and a sunny day is 0.088 or nine basis points. While nine basis points is approximately how much the markets go up on an average day, it is only about five percent of the standard deviation of daily returns. Consistent with this calculation, the $\mathrm{R}^{2}$ of the naive pooled regression reported in Table III is 0.02 percent, a very low number.

It is, of course, not reasonable to expect the explanatory power of sunshine to be large. Many shocks affect daily stock returns, such as real news about global, national, and local fundamentals. Unless the market is entirely inefficient, fundamental news must have a large effect on returns.

Rather than focusing on $\mathrm{R}^{2}$, we next consider whether a portfolio strategy based on weather trading can significantly increase the Sharpe ratio of a hypothetical investor. We employ a Britten-Jones (1999) test of the mean-variance efficiency of a simple global market portfolio, and the global portfolio combined with a weather-based strategy. The BrittenJones test regresses a vector of ones on portfolio returns. When more than one set of portfolio returns are used as dependent variables, a mean-variance efficient portfolio will be significantly related to the vector of ones and all other portfolios will be unrelated to the vector of ones. The intuition behind the test is that a vector of ones represents the ideal asset return - the returns are positive with no variability. Put differently, the vector of ones represents the returns of an asset with an infinite Sharpe ratio, having a mean of one and a variance of zero. The regression finds the combination of potentially mean-variance efficient portfolios that most closely approximates this ideal asset return.

Our global market portfolio is the equal-weighted portfolio of all cities' returns in local 
currencies. To construct our trading strategy returns, we average $\mathrm{SKC}_{i, t}$ for each city from 5 a.m. to 8 a.m. each morning. We then deseasonalize the morning SKC variable in the same way that we deseasonalize the previous measure of SKC (described in section II). Finally, we calculate the equal-weighted average return of cities with positive deseasonalized morning SKC and the equal-weighted average return of cities with negative deseasonalized morning SKC. We consider strategies that are long indices with sunny cities, short indices with cloudy cities, and both long the sunny indices and short the cloudy indices. The results of our test appear in Table VI.

Table VI shows that investors can improve their Sharpe ratios by trading on the weather. Looking at the first model, the returns of the sunny strategy are given almost the same weight in the mean-variance efficient portfolio as the returns of the global market portfolio. The weight on the sunny strategy returns is statistically significant, with a $t$-statistic of 3.39. Looking at the second model, the mean-variance efficient portfolio is clearly short the cloudy portfolio. The $t$-statistics of the weight of the cloudy portfolio is -3.22 . The results of the third model are somewhat ambiguous, presumably because of a high degree of multicollinearity in the regression. However, the fourth model again implies that trading on the weather can increase a Sharpe ratio. The strategy of buying the sunny portfolio and selling the cloudy portfolio is clearly a significant part of the global mean-variance efficient portfolio.

\section{E. Accounting for Transactions Costs}

The results in Table VI are calculated without considering transactions costs. To determine whether exploiting the sunshine effect can increase a Sharpe ratio after accounting for reasonable costs, we approximate the costs involved in trading one S\&P 500 index futures contract with some conservative back-of-the-envelope calculations. Huang and Stoll (1997) find that brokerage commissions for trading one S\&P futures contract are generally less than $\$ 25$ per contract for institutional clients. Manaster and Mann (1996)) find that the bid-ask spread that S\&P 500 futures customers typically pay is $\$ 4.33$, so we estimate total costs of trading as $\$ 30$ per contract. Each contract's notional value is $\$ 250$ times the level of the index, which is currently close to 1200 . Thus, the notional value of one contract is 
approximately $\$ 300,000$ and the cost of trading one S\&P 500 futures contract as a fraction of the contract's value appears to be approximately one basis point.

With a transactions costs estimate of one basis point, we can determine how much transactions costs detract from the profitability of a weather trading strategy. We calculate the returns to a strategy that is long the market index of each city for which the average cloud cover variable between 5 a.m. and 8 a.m. is between zero and four, and short the city's index otherwise. Each city for which the strategy stipulates a long position receives a weight of $1 / n$ (where $n$ is the number of cities considered by the strategy) while each city for which the strategy stipulates a short position receives a weight of $-1 / n$. Since the number of cloudy cities varies from day to day, this trading rule requires a positive net investment on some days and a negative net investment on other days. If the trading rule implies that the position in a particular city changes from a long to a short position or from a short to a long position, we subtract transactions costs from the return of the city on that day. After calculating the returns to this strategy, we ask whether this strategy return should receive positive weight in a mean-variance efficient portfolio using the Britten-Jones test described above.

Performing the tests with costs of two basis points (one for reversing a previous position, one for establishing a new position), the Britten-Jones test assigns a weight of 34.02 ( $\mathrm{t}=$ 11.20) to the market portfolio and a weight of $20.21(\mathrm{t}=4.29)$ to the weather strategy. For comparison, with no transactions costs the Britten-Jones test gives optimal weights of $36.11(\mathrm{t}=11.92)$ and $26.07(\mathrm{t}=5.56)$ respectively. Increasing the costs to four basis points results in weights of $31.89(\mathrm{t}=10.46)$ and $14.28(\mathrm{t}=4.72)$, while increasing costs to six basis points results in weights of $29.73(\mathrm{t}=9.73)$ and $8.32(\mathrm{t}=1.76)$. Thus, even if index futures transactions costs are twice as high as our estimates for the S\&P 500 contracts, trading on the sunshine effect can improve the Sharpe ratio of an investor's portfolio.

Overall, the mean-variance improvement possible through weather-based trading strategies implies that the sunshine effect is economically significant. Of course, the sunshine effect does not represent a riskfree arbitrage opportunity, merely an improvement in the daily Sharpe ratio. While the daily Sharpe ratio of the market portfolio is 0.164 in our sample, with zero transactions costs, the sunshine-based trading strategy increases the daily Sharpe ratio to 0.186 . This translates into an average annualized return of 32.35 percent for 
a portfolio that matches the risk of the market portfolio. This compares with an average annualized return of 28.08 percent for the market portfolio. For the optimal sunshine-based strategy that accounts for transactions costs of two basis points per portfolio adjustment, the daily Sharpe ratio of is 0.177 . Translated into annualized returns, the optimal sunshine portfolio (again with trading costs of two basis points) on average earns 30.67 percent per year. Thus, after accounting for realistic transactions costs, trading on the sunshine effect produces statistically significant, somewhat modest but non-negligible improvements in portfolio Sharpe ratios.

\section{Conclusion}

Psychological evidence and casual intuition predict that sunny weather is associated with upbeat mood. This paper examines the relation between whether a day is sunny and stock returns that day at 26 stock exchanges internationally from 1982-97. We find that sunshine is highly significantly correlated with daily stock returns. After controlling for sunshine, other weather conditions such as rain and snow are unrelated to returns. While the weather effect does not represent a riskfree arbitrage opportunity, it is possible to improve the Sharpe ratio of the market portfolio, though somewhat modestly, by trading on the weather, even when there are transactions costs. These results are difficult to reconcile with fully rational price-setting.

Well known patterns of return predictability, such as size and value effects, have been interpreted by many as indicating market inefficiency. However, others have attempted to rationalize stock price patterns as resulting from risk premia instead of psychological effects. This study offers some evidence that is tough to rationalize. The evidence is not a result of datasnooping - the psychological hypothesis is the stimulus for exploring sunshine effects. There is no very appealing rational explanation for why a day of sunshine near a country's stock exchange should be associated with high returns on a national market index, nor why morning sunshine should predict subsequent returns. This evidence is, however, consistent with sunlight affecting mood, and mood affecting prices.

Our findings suggest that those investors who can trade a stock index with small transaction costs (most investors) could have benefited somewhat modestly from weather-based 
trading strategies. But we think the main practical implication of our findings is somewhat less direct. Our results suggest that investors can benefit from becoming aware of their moods, in order to avoid mood-based errors in their judgments and trades. ${ }^{8}$ A useful direction for future experimental research will be to examine the effects of mood or weather on trading behavior, and the extent to which investors who are primed to attend to their moods can make better decisions.

Our findings, in conjunction with psychological literature, also suggest that it may be valuable to explore how weather or other mood proxies affect the stock market response to news events. Some of these effects can be subtle. ${ }^{9}$ The simplest hypothesis is that good mood will make the reaction to news events more favorable. However, the evidence discussed earlier about differences in information processing styles suggests a more mixed outcome. Individuals in bad moods, who process information more carefully, should react more strongly to truly relevant news, whether good or bad, and should be careful to avoid reacting to irrelevant pseudo-news. In contrast, individuals in good moods should be more prone to reacting to irrelevant announcements.

Recently evidence has been provided that security prices, including stock market prices, react to the salient publication of information that is irrelevant, or that is already publicly available; and that the reaction to information is affected by the form in which it is presented. ${ }^{10}$ Psychological evidence on the effect of mood on information processing style suggests that it would be interesting to examine whether stock market reactions to redundant or irrelevant news is greater when mood is good (e.g., weather is sunny) than when mood is bad.

Our findings also suggest some broader implications for asset pricing. Sunshine is just one of many influences on mood. In confirming the effect of mood on asset prices, this study

\footnotetext{
${ }^{8}$ Obviously weather is just one example of a mood-influencing factor that an investor may be able to discount for by paying attention to the sources of his mood. On a given day an individual who pauses to consider may be able to identify other influences, such as uncomfortable new shoes, a broken air-conditioner, the triumph of a child in school or of a popular local sports team, news of a promotion at work, or of the nation's victory or defeat in war.

${ }^{9}$ We are grateful to Norbert Schwarz for insightful comments in this regard.

10 See Andrade (1999), Ashton (1976), Avery and Chevalier (1999), Cooper, Dimitrov, and Rau (2001), Hand (1990, 1991), Ho and Michaely (1988), Huberman and Regev (2001), Klibanoff, Lamont, and Wizman (1999), Rashes (2001). There is both experimental and capital markets evidence on accounting information in particular (see, e.g., Ashton (1976), Dietrich et al (2000), Hopkins (1996), Maines and McDaniel (2000), and the review of of experimental research of Libby, Bloomfield, and Nelson (2001)).
} 
suggests that other mood effects may be important. For example, as discussed in Section I, negative moods tend to stimulate effort at careful analysis, whereas positive moods are associated with less critical and more receptive information processing. This suggests that after positive events have put people in a good mood, they will be more prone to accepting new theories of how the market works. The 1990s were certainly a period of positive mood in America, owing to the great success of the U.S. economy and stock market, along with U.S. predominance as the sole world superpower. It is tempting to conclude that this positive mood made investors more receptive to 'new economy' theories of the world, resulting in an internet bubble.

A possible explanation for momentum in individual stock returns is that low returns on a stock put the investor clientele of that stock in a negative, critical mood. This bad mood in turn may cause skeptical and pessimistic interpretation of subsequently arriving information. There is evidence that people have trouble foreseeing their future moods and how this will affect their future behavior (a phenomenon known as projection bias; see, e.g., Loewenstein, O’Donoghue, and Rabin (2000) and the discussion in Mehra and Sah (2000)). This suggests that people will not fully foresee their negative interpretation of future information, causing a tendency toward a further drop in price.

These speculations about momentum and overreaction deserve further study. But there are other possible hypotheses that can be explored. The broadest message of this paper is that to understand security price movements, it is important to go beyond the statistical behavior of prices and fundamentals to study what influences investor moods and emotions. 


\section{References}

Andrade, G. M., 1999, Do appearances matter? the impact of EPS accretion and dilution on stock prices, Harvard University Working Paper.

Ashton, R. H., 1976, Cognitive changes induced by accounting changes: Experimental evidence on the functional fixation hypothesis, Journal of Accounting Research 14, 1.

Avery, C., and J. Chevalier, 1999, Identifying investor sentiment from price paths: The case of football betting, Journal of Business 72, 493-521.

Boudoukh, J., M. P. Richardson, M. Subrahmanyam, and R. F. Whitelaw, 2000, The last great arbitrage: Exploiting the buy-and-hold mutual fund investor, Working paper, New York University.

Britten-Jones, M., 1999, The sampling error in estimates of mean-variance efficient portfolio weights, Journal of Finance 54, 655-671.

Clore, G. L., and W. G. Parrott, 1991, Moods and their vicissitudes: Thoughts and feelings as information, in J. Forgas, ed.: Emotion and Social Judgments pp. 107-123 (Pergamon Press, Oxford).

Clore, G. L., N. Schwarz, and M. Conway, 1994, Affective causes and consequences of social information processing, in Jr. Robert S. Wyer, and Thomas K. Srull, ed.: Handbook of Social Cognition, 2nd edition (Lawrence Erlbaum, Hillsdale, NJ).

Cooper, M. J., O. Dimitrov, and P. R. Rau, 2001, A Rose.com by any other name, Journal of Finance 56.

Dietrich, J. R., S. J. Kachelmeier, D. N. Kleinmuntz, and T. J. Linsmeier, 2000, Market efficiency, bounded rationally and supplemental business reporting disclosures, forthcoming, Journal of Accounting Research.

Eagles, J. M., 1994, The relationship between mood and daily hours of sunlight in rapid cycling bipolar illness, Biological Psychiatry 36, 422-424. 
Forgas, J. P., 1995, Mood and judgment: The affect infusion model (aim), Psychological Bulletin 117, 39-66.

Frijda, N., 1988, The laws of emotion, Cognition and Emotion 1, 235-258.

Hand, J. R. M., 1990, A test of the extended functional fixation hypothesis, Accounting Review 65, 740-63.

Hand, J. R. M., 1991, Extended functional fixation and security returns around earnings announcements: A reply to Ball and Kothari, Accounting Review 66, 739-46.

Ho, T., and R. Michaely, 1988, Information quality and market efficiency, Journal of Financial and Quantitative Analysis 5, 357-386.

Hong, H., J. Kubik, and J. C. Stein, 2001, Social interactions and stock market participation, Stanford Business School Working Paper.

Hopkins, P., 1996, The effect of financial statement classification of hybrid financial instruments on financial analysts' stock price judgments, Journal of Accounting Research 34, $33-50$.

Huang, R. D., and H. R. Stoll, 1997, Is it time to split the S \& P 500 futures contract?, working paper 97-03, Vanderbilt University Financial Markets Research Center.

Huberman, G., and T. Regev, 2001, Contagious speculation and a cure for cancer, Journal of Finance 56, 387-396.

Johnson, E. J., and A. Tversky, 1983, Affect, generalization, and the perception of risk, Journal of Personality and Social Psychology 45, 20-31.

Kamstra, M. J., L. A. Kramer, and M. D. Levi, 2000a, Losing sleep at the market: The daylight-savings anomaly, American Economic Review, forthcoming 90, 1005-1011.

Kamstra, M. J., L. A. Kramer, and M. D. Levi, 2000b, Winter blues: Seasonal affective disorder (SAD), the january effect, and stock market returns, Faculty of Commerce, University of British Columbia Working Paper. 
Keim, D. B., 1983, Size related anomalies and stock return seasonality: Further evidence, Journal of Financial Economics 12, 13-32.

Klibanoff, P., O. Lamont, and T. A. Wizman, 1999, Investor reaction to salient news in closed-end country funds, Journal of Finance 53, 673-699.

Kramer, L. A., 2000, Intraday stock returns, time-varying risk premia, and diurnal mood variation, Department of Economics, Simon Fraser University Working Paper.

Libby, R., R. Bloomfield, and M. Nelson, 2001, Experimental research in financial accounting, Cornell University.

Loewenstein, G., T. O’Donoghue, and M. Rabin, 2000, Projection bias in predicting future utility, University of California, Berkeley Working Paper E00-284.

Loewenstein, G., E. Weber, C. Hsee, and N. Welch, 2001, Risk as feelings, Psychological Bulletin, forthcoming.

Loewenstein, G. F., 1996, Out of control: Visceral influences on behavior, Organizational Behavior and Human Decision Processes 65, 272-292.

Loewenstein, G. F., 2000, Emotions in economic theory and economic behavior, American Economic Review 65, 426-432.

Mackie, D. M., and L. T. Worth, 1991, Feeling good, but not thinking straight: the impact of positive mood on persuasion, in J. Forgas, ed.: Emotion and Social Judgments pp. 201-219 (Pergamon, Oxford).

Maines, L. A., and L. S. McDaniel, 2000, Effects of comprehensive-income characteristics on nonprofessional investors' judgments: The role of financial-statement presentation format, Accounting Review 75, 179-207.

Manaster, S., and S. C. Mann, 1996, Life in the pits: Competitive market making and inventory control, Review of Financial Studies 9, 953-975.

Mehra, R., and R. Sah, 2000, Mood, projection bias and equity market volatility, University of California, Santa Barbara. 
Petty, R. E., F. Gleicher, and S. M. Baker, 1991, Multiple roles for affect in persuasion, in J. Forgas, ed.: Emotion and Social Judgments pp. 181-200 (Pergamon, Oxford).

Rashes, M. S., 2001, Massively confused investors making conspicuously ignorant choices (MCI - MCIC), Journal of Finance 56, 1911-1928.

Rind, B., 1996, Effects of beliefs about weather conditions on tipping, Journal of Applied Social Psychology 26, 137-147.

Roll, R. W., 1992, Weather, in Peter Newman, Murray Milgate, and John Eatwell, ed.: The New Palgrave Dictionary of Money and Finance 3, 789-790 (Macmillan Press, London).

Saunders, E. M. J., 1993, Stock prices and wall street weather, American Economic Review 83, 1337-1345.

Schwarz, N., 1990, Feelings as information. informational and motivational functions of affective states, in R. Sorrentino, and E.T. Higgins, ed.: Handbook of Motivation and Cognition 2, 527-561 (Guilford Press, New York).

Schwarz, N., and H. Bless, 1991, Happy and mindless, but sad and smart? the impact of affective states on analytic reasoning, in J. Forgas, ed.: Emotion and Social Judgments pp. 55-71 (Pergamon, Oxford).

Schwarz, N., and G. L. Clore, 1983, Mood, misattribution, and judgments of well-being: Informative and directive functions of affective states, Journal of Personality and Social Psychology 45, 513-523.

Shiller, R. J., 1984, Stock prices and social dynamics, Brookings Papers on Economic Activity Review 2, 457-498.

Shiller, R. J., 1990, Speculative prices and popular models, Journal of Economic Perspectives $4,55-65$.

Shiller, R. J., 2000a, Conversation, information, and herd behavior, American Economic Review 85, 181-185. 
Shiller, R. J., 2000b, Measuring bubble expectations and investor confidence, Journal of Psychology and Financial Markets 1, 49-60.

Tietjen, G. H., and D. F. Kripke, 1994, Suicides in california (1968-1977) - absence of seasonality in los angeles and sacramento counties, Psychiatric Research 53, 161-172.

Trombley, M. A., 1997, Stock prices and Wall street weather: Additional evidence, Quarterly Journal of Business and Economics 36, 11-21.

Wilson, T. D., and J. Schooler, 1991, Thinking too much: Introspection can reduce the quality of preferences and decisions, Journal of Personality and Social Psychology 60, $181-192$.

Wright, W. F., and G. H. Bower, 1992, Mood effects on subjective probability assessment, Organizational Behavior and Human Decision Processes 52, 276-291. 


\section{Table I}

Summary Statistics

Table I displays a number of summary statistics that describe the sample. All returns are expressed in percentage terms in local currencies, and all sample periods end on december 31, 1997. The variable described as cover is total sky cover, taken from the ISWO dataset. Cloud cover ranges from 0 to 8 in any particular city at any particular time.

\begin{tabular}{lccccc}
\hline Location & Begin Date & Mean Cover & STD Cover & Mean Ret & STD Ret \\
\hline Amsterdam & 1982 & 5.39 & 2.28 & 0.057 & 0.89 \\
Athens & 1988 & 3.23 & 2.55 & 0.097 & 1.81 \\
Buenos Aires & 1988 & 4.35 & 2.71 & 0.496 & 4.13 \\
Bangkok & 1982 & 5.51 & 1.59 & 0.056 & 1.46 \\
Brussels & 1982 & 5.09 & 2.32 & 0.057 & 0.79 \\
Copenhagen & 1982 & 5.35 & 2.31 & 0.059 & 0.88 \\
Dublin & 1982 & 5.84 & 1.85 & 0.069 & 1.06 \\
Helsinki & 1987 & 5.47 & 2.39 & 0.044 & 1.12 \\
Istanbul & 1988 & 3.85 & 2.58 & 0.269 & 2.63 \\
Johannesburg & 1982 & 3.00 & 2.52 & 0.075 & 1.25 \\
Kuala Lumpur & 1982 & 6.80 & 0.43 & 0.019 & 1.44 \\
London & 1982 & 5.74 & 2.00 & 0.054 & 0.86 \\
Madrid & 1982 & 3.42 & 2.74 & 0.067 & 1.06 \\
Manila & 1986 & 5.31 & 1.92 & 0.108 & 1.95 \\
Milan & 1982 & 4.29 & 2.95 & 0.052 & 1.24 \\
New York & 1982 & 4.95 & 2.72 & 0.058 & 0.92 \\
Oslo & 1982 & 5.40 & 2.37 & 0.068 & 1.39 \\
Paris & 1982 & 5.25 & 2.41 & 0.054 & 1.03 \\
Rio de Janeiro & 1982 & 5.17 & 2.46 & 0.806 & 3.79 \\
Santiago & 1987 & 3.28 & 3.07 & 0.112 & 1.00 \\
Singapore & 1982 & 6.70 & 0.91 & 0.025 & 1.16 \\
Stockholm & 1982 & 5.49 & 2.25 & 0.074 & 1.23 \\
Sydney & 1982 & 4.15 & 2.40 & 0.048 & 1.09 \\
Taipei & 1982 & 5.55 & 2.12 & 0.088 & 2.08 \\
Vienna & 1982 & 5.03 & 2.59 & 0.056 & 0.95 \\
Zurich & 1982 & 5.33 & 2.57 & 0.067 & 0.82 \\
\hline
\end{tabular}




\section{Table II}

Correlation Matrix

Table II displays estimated cross-city correlation coefficients for the principal variables in the analysis. Correlations of deseasonalized cloudiness appear above the diagonal, while returns correlations appear below the diagonal. Almost all correlations with an absolute value greater than 0.04 are statistically significant.

\begin{tabular}{|c|c|c|c|c|c|c|c|c|c|c|c|c|c|}
\hline & Ams & Ath & Bue & Ban & Bru & Cop & Dub & Hel & Ist & Joh & Kua & Lon & Mad \\
\hline Ams & 口 & -.06 & -.01 & -.01 & .74 & .29 & .12 & .12 & -.08 & .02 & .01 & .43 & -.07 \\
\hline Ath & .12 & $\boldsymbol{\square}$ & .02 & -.05 & -.07 & -.02 & .04 & -.03 & .41 & .00 & -.02 & -.01 & -.00 \\
\hline Bue & .08 & .03 & $\mathbf{\square}$ & .01 & -.01 & .01 & -.01 & .00 & .02 & .02 & .02 & -.01 & -.01 \\
\hline Ban & .07 & .10 & .05 & 口 & -.02 & -.00 & -.02 & -.02 & -.04 & -.01 & .02 & -.03 & .01 \\
\hline Bru & .46 & .16 & .07 & .12 & 口 & .25 & .10 & .09 & -.09 & .02 & .00 & .40 & -.09 \\
\hline Cop & .29 & .15 & .05 & .11 & .28 & $\square$ & .04 & .19 & -.04 & .02 & -.01 & .12 & -.05 \\
\hline Dub & .39 & .17 & .05 & .12 & .29 & .29 & $\square$ & -.02 & .00 & .00 & .00 & .37 & -.03 \\
\hline Hel & .32 & .07 & .05 & .10 & .26 & .33 & .25 & $\boldsymbol{\square}$ & -.04 & -.00 & -.04 & .03 & -.06 \\
\hline Ist & .03 & .09 & .01 & .05 & .02 & .06 & .08 & .05 & $\square$ & -.01 & -.00 & -.03 & .01 \\
\hline Joh & .19 & .11 & .00 & .08 & .14 & .17 & .19 & .27 & .06 & 口 & .02 & -.01 & -.01 \\
\hline Kua & .20 & .16 & .03 & .22 & .22 & .21 & .21 & .19 & .04 & .19 & 口 & -.00 & .02 \\
\hline Lon & .63 & .10 & .09 & .08 & .35 & .24 & .40 & .28 & .05 & .21 & .21 & 口 & -.01 \\
\hline Mad & .32 & .17 & .09 & .15 & .36 & .24 & .28 & .28 & .03 & .18 & .20 & .29 & 口 \\
\hline Man & .08 & .09 & .03 & .16 & .06 & .14 & .11 & .12 & .03 & .13 & .20 & .08 & .12 \\
\hline Mil & .27 & .10 & .06 & .13 & .28 & .22 & .21 & .27 & .03 & .13 & .15 & .24 & .30 \\
\hline New & .34 & .05 & .11 & .03 & .23 & .08 & .12 & .10 & .01 & .02 & .11 & .35 & .13 \\
\hline Osl & .46 & .13 & .07 & .11 & .36 & .28 & .34 & .30 & .02 & .22 & .24 & .39 & .30 \\
\hline Par & .55 & .14 & .09 & .08 & .47 & .26 & .33 & .27 & .04 & .18 & .19 & .47 & .37 \\
\hline Rio & .08 & .03 & .08 & .02 & .08 & .08 & .05 & .11 & .03 & .04 & .08 & .08 & .06 \\
\hline San & .16 & .06 & .13 & .08 & .19 & .12 & .13 & .08 & .03 & .09 & .13 & .15 & .17 \\
\hline Sin & .25 & .17 & .06 & .22 & .26 & .26 & .27 & .24 & .06 & .22 & .65 & .26 & .28 \\
\hline Sto & .43 & .18 & .08 & .13 & .38 & .28 & .31 & .39 & .06 & .16 & .21 & .36 & .37 \\
\hline Syd & .30 & .11 & .04 & .16 & .25 & .30 & .30 & .32 & .06 & .34 & .29 & .29 & .32 \\
\hline Tai & .05 & .12 & .01 & .10 & .08 & .06 & .10 & .07 & .07 & .06 & .11 & .05 & .12 \\
\hline Vie & .24 & .17 & .06 & .17 & .28 & .22 & .24 & .24 & .11 & .16 & .22 & .18 & .32 \\
\hline Zur & .61 & .19 & .07 & .13 & .51 & .34 & .40 & .33 & .03 & .24 & .28 & .48 & .42 \\
\hline
\end{tabular}


Table II continued

\begin{tabular}{|c|c|c|c|c|c|c|c|c|c|c|c|c|c|}
\hline & Man & Mil & New & Osl & Par & Rio & San & Sin & Sto & Syd & Tai & Vie & Zur \\
\hline Ams & -.03 & .01 & .00 & .14 & .46 & .03 & -.01 & .01 & .15 & -.01 & -.02 & .13 & .15 \\
\hline Ath & -.01 & -.09 & -.02 & .01 & -.09 & -.00 & .01 & -.02 & -.02 & -.02 & -.02 & -.05 & -.03 \\
\hline Bue & -.03 & -.00 & .00 & .01 & -.01 & -.19 & .22 & -.01 & .01 & -.01 & .03 & .01 & -.00 \\
\hline Ban & .07 & -.00 & .01 & -.04 & -.00 & -.03 & -.00 & .02 & -.02 & .01 & .03 & -.02 & -.01 \\
\hline Bru & -.02 & .05 & -.01 & .10 & .64 & .01 & -.01 & -.01 & .14 & -.03 & -.03 & .16 & .24 \\
\hline Cop & .00 & .03 & .00 & .34 & .16 & .02 & -.02 & .03 & .36 & -.00 & -.01 & .10 & .10 \\
\hline Dub & -.01 & -.03 & -.02 & .00 & .10 & -.02 & .01 & -.00 & .00 & .01 & -.00 & .02 & .05 \\
\hline Hel & .03 & .00 & .00 & .12 & .07 & .03 & .00 & .01 & .40 & .02 & .02 & .06 & .04 \\
\hline Ist & -.00 & -.12 & -.00 & .01 & -.12 & .00 & -.00 & -.02 & -.04 & -.00 & -.00 & -.13 & -.09 \\
\hline Joh & .00 & .02 & .01 & .01 & .03 & .03 & .02 & -.01 & .03 & -.02 & -.01 & .03 & .03 \\
\hline Kua & .03 & .01 & -.00 & -.04 & .01 & -.02 & .01 & .19 & -.03 & .02 & .04 & -.00 & .00 \\
\hline Lon & -.02 & .00 & -.02 & .08 & .41 & .01 & .00 & -.00 & .04 & -.01 & -.01 & .05 & .09 \\
\hline Mad & -.01 & .21 & .00 & -.01 & -.04 & -.00 & -.02 & -.02 & -.06 & -.01 & -.01 & -.07 & -.02 \\
\hline Man & घ & -.02 & -.01 & -.01 & -.02 & .02 & -.03 & .05 & -.01 & .01 & -.01 & -.01 & -.02 \\
\hline Mil & .06 & च & -.01 & .07 & .13 & -.01 & -.00 & -.01 & .03 & .01 & .03 & .07 & .31 \\
\hline New & -.01 & .12 & $\square$ & -.03 & -.01 & .02 & .00 & -.00 & -.02 & .03 & .01 & .01 & -.01 \\
\hline Osl & .11 & .23 & .13 & च & .11 & .02 & .01 & .00 & .40 & .01 & .02 & .01 & .06 \\
\hline Par & .05 & .29 & .27 & .37 & च & .03 & .00 & .02 & .10 & -.03 & -.01 & .11 & .29 \\
\hline Rio & .03 & .05 & .09 & .09 & .10 & 口 & -.09 & -.04 & .00 & -.00 & -.02 & -.01 & .01 \\
\hline San & .04 & .12 & .17 & .17 & .18 & .13 & 口 & -.04 & -.01 & .00 & .03 & -.01 & -.01 \\
\hline Sin & .25 & .19 & .11 & .29 & .22 & .06 & .13 & च & -.02 & .02 & -.01 & -.00 & -.00 \\
\hline Sto & .10 & .27 & .18 & .39 & .41 & .10 & .17 & .27 & 口 & .01 & -.00 & .07 & .07 \\
\hline Syd & .21 & .19 & .05 & .35 & .22 & .09 & .13 & .41 & .31 & $\square$ & -.02 & -.02 & -.02 \\
\hline Tai & .08 & .08 & -.00 & .05 & .06 & .01 & .05 & .13 & .08 & .11 & [ & -.01 & -.02 \\
\hline Vie & .16 & .24 & .08 & .23 & .26 & .07 & .08 & .24 & .27 & .22 & .13 & - & .29 \\
\hline Zur & .11 & .34 & .29 & .47 & .56 & .11 & .21 & .34 & .50 & .35 & .09 & .33 & a \\
\hline
\end{tabular}




\section{Table III}

Sunshine Regression and Logit Model Results

This table displays city-by-city and pooled results of estimating a regression of daily stock returns on cloudiness and a logit model that relates the probability of a positive daily stock return to cloudiness. The regression results appear in columns three and four, while the logit results appear in columns five to seven. An asterisk indicates statistical significance at the $5 \%$ level or greater.

\begin{tabular}{lcccccc}
\hline & \multicolumn{3}{c}{ OLS Regression } & \multicolumn{3}{c}{ Logit Model } \\
\hline Location & Observations & $\beta_{i C}$ & $t$-Statistic & $\gamma_{i C}$ & $\chi^{2}$ & P-Value \\
\hline Amsterdam & 3984 & -0.007 & -1.07 & -0.024 & 2.76 & 0.0963 \\
Athens & 2436 & 0.012 & 0.71 & -0.014 & 0.53 & 0.4649 \\
Buenos Aires & 2565 & -0.030 & -0.98 & -0.019 & 1.60 & 0.2054 \\
Bangkok & 3617 & 0.009 & 0.45 & -0.014 & 0.24 & 0.6259 \\
Brussels & 3997 & $-0.018^{*}$ & -3.25 & $-0.036^{*}$ & 6.75 & 0.0094 \\
Copenhagen & 4042 & -0.002 & -0.30 & -0.002 & 0.02 & 0.8999 \\
Dublin & 3963 & -0.000 & -0.02 & -0.025 & 2.13 & 0.1445 \\
Helsinki & 2725 & -0.016 & -1.67 & $-0.034^{*}$ & 4.01 & 0.0452 \\
Istanbul & 2500 & 0.007 & 0.32 & -0.001 & 0.00 & 0.9488 \\
Johannesburg & 3999 & 0.004 & 0.47 & -0.012 & 0.67 & 0.4124 \\
Kuala Lumpur & 3863 & 0.014 & 0.26 & -0.109 & 1.99 & 0.1586 \\
London & 4003 & -0.010 & -1.52 & -0.019 & 1.41 & 0.2355 \\
Madrid & 3760 & -0.011 & -1.60 & -0.015 & 1.41 & 0.2353 \\
Manila & 2878 & 0.018 & 0.83 & 0.003 & 0.02 & 0.9023 \\
Milan & 3961 & $-0.014^{*}$ & -2.03 & -0.021 & 3.69 & 0.0549 \\
New York & 4013 & -0.007 & -1.28 & $-0.035^{*}$ & 8.64 & 0.0033 \\
Oslo & 3877 & -0.018 & -1.92 & -0.025 & 3.31 & 0.0688 \\
Paris & 3879 & -0.009 & -1.27 & $-0.027^{*}$ & 3.93 & 0.0474 \\
Rio de Janeiro & 2988 & -0.057 & -1.93 & -0.016 & 0.96 & 0.3267 \\
Santiago & 2636 & 0.000 & 0.05 & -0.012 & 0.73 & 0.3935 \\
Singapore & 3890 & 0.008 & 0.37 & -0.002 & 0.00 & 0.9588 \\
Stockholm & 3653 & -0.014 & -1.54 & -0.025 & 2.89 & 0.0889 \\
Sydney & 4037 & $-0.014^{*}$ & -1.96 & -0.020 & 2.16 & 0.1417 \\
Taipei & 3784 & -0.016 & -0.97 & -0.013 & 0.66 & 0.4164 \\
Vienna & 3907 & $-0.013^{*}$ & -2.14 & $-0.026^{*}$ & 4.11 & 0.0425 \\
Zurich & 3851 & -0.007 & -1.28 & -0.012 & 0.89 & 0.3465 \\
\hline All Cities (naive) & 92808 & $-0.011^{*}$ & -4.49 & $-0.020^{*}$ & 43.62 & 0.0001 \\
All Cities (PCSE) & 92808 & $-0.010^{*}$ & -3.96 & - & - & - \\
\hline & & & & & &
\end{tabular}




\section{Table IV}

Sunshine Regressions Controlling for Other Weather Conditions

This table displays city-by-city and pooled results of estimating a regression of daily stock returns on cloudiness, raininess, and snowiness. An asterisk indicates statistical significance at the $5 \%$ level or greater.

\begin{tabular}{|c|c|c|c|c|}
\hline Location & $\overline{\beta_{i C}}$ & $t$-Statistic & $\overline{\beta_{i R}}$ & $\overline{\beta_{i S}}$ \\
\hline Amsterdam & -0.005 & -0.69 & -0.064 & -0.075 \\
\hline Athens & 0.014 & 0.77 & -0.295 & -0.393 \\
\hline Buenos Aires & -0.022 & -0.64 & -0.580 & 2.226 \\
\hline Bangkok & 0.014 & 0.63 & -0.566 & 0.392 \\
\hline Brussels & -0.011 & -1.76 & $-0.219^{*}$ & 0.123 \\
\hline Copenhagen & -0.001 & -0.10 & -0.193 & 0.264 \\
\hline Dublin & 0.001 & 0.08 & -0.018 & 0.111 \\
\hline Helsinki & -0.016 & -1.51 & 0.319 & -0.397 \\
\hline Istanbul & 0.008 & 0.33 & -0.340 & 2.575 \\
\hline Johannesburg & 0.003 & 0.28 & 0.090 & 0.044 \\
\hline Kuala Lumpur & 0.021 & 0.38 & -0.206 & -0.023 \\
\hline London & -0.009 & -1.14 & -0.052 & -0.019 \\
\hline Madrid & -0.011 & -1.42 & 0.031 & -0.411 \\
\hline Manila & 0.015 & 0.63 & 0.234 & -2.318 \\
\hline Milan & $-0.015^{*}$ & -1.99 & 0.342 & -1.026 \\
\hline New York & -0.002 & -0.31 & $-1.929 *$ & -1.555 \\
\hline Oslo & -0.019 & -1.76 & 0.035 & 0.078 \\
\hline Paris & -0.012 & -1.53 & 0.279 & 0.378 \\
\hline Rio de Janeiro & $-0.067^{*}$ & -2.16 & 1.135 & 2.805 \\
\hline Santiago & 0.001 & 0.17 & -0.409 & -1.154 \\
\hline Singapore & 0.007 & 0.32 & 0.095 & -0.377 \\
\hline Stockholm & -0.012 & -1.22 & 0.094 & -0.594 \\
\hline Sydney & -0.013 & -1.51 & -0.073 & 0.459 \\
\hline Taipei & -0.020 & -1.13 & 0.212 & 3.378 \\
\hline Vienna & $-0.013^{*}$ & -2.00 & 0.005 & 0.009 \\
\hline Zurich & -0.002 & -0.31 & -0.101 & -0.015 \\
\hline All Cities (naive) & $-0.010^{*}$ & -3.94 & -0.058 & 0.076 \\
\hline All Cities (PCSE) & $-0.009^{*}$ & -3.47 & -0.065 & 0.067 \\
\hline
\end{tabular}




\section{Table V}

Sunshine Logit Models Controlling for Other Weather Conditions

This table displays city-by-city and pooled results of estimating a logit model that relates the probability of a positive daily stock return to cloudiness, raininess, and snowiness. An asterisk indicates statistical significance at the $5 \%$ level or greater.

\begin{tabular}{lcccr}
\hline Location & $\gamma_{i C}$ & $\chi^{2}$ & $\gamma_{i R}$ & \multicolumn{1}{c}{$\gamma_{i S}$} \\
\hline Amsterdam & -0.028 & 3.04 & 0.133 & 0.023 \\
Athens & -0.014 & 0.51 & 0.357 & -2.819 \\
Buenos Aires & -0.012 & 0.51 & -0.254 & -0.272 \\
Bangkok & -0.007 & 0.05 & -0.810 & -0.207 \\
Brussels & -0.019 & 1.42 & $-0.565^{*}$ & 0.474 \\
Copenhagen & 0.002 & 0.01 & -0.435 & 0.103 \\
Dublin & -0.012 & 0.40 & -0.225 & 0.739 \\
Helsinki & $-0.038^{*}$ & 4.07 & 0.606 & -0.130 \\
Istanbul & 0.003 & 0.02 & -0.557 & 1.441 \\
Johannesburg & -0.016 & 1.05 & 0.166 & 0.298 \\
Kuala Lumpur & -0.103 & 1.74 & -0.277 & 0.310 \\
London & -0.007 & 0.16 & -0.330 & -0.034 \\
Madrid & -0.018 & 1.59 & 0.300 & 0.989 \\
Manila & 0.005 & 0.04 & -0.151 & 0.605 \\
Milan & -0.021 & 2.94 & 0.180 & -1.742 \\
New York & $-0.025^{*}$ & 4.14 & $-4.943^{*}$ & 2.636 \\
Oslo & -0.024 & 2.45 & 0.021 & -0.120 \\
Paris & $-0.031^{*}$ & 4.46 & 0.242 & 2.060 \\
Rio de Janeiro & -0.022 & 1.83 & 0.945 & 0.472 \\
Santiago & -0.009 & 0.34 & -1.074 & -1.615 \\
Singapore & -0.008 & 0.05 & 0.417 & -0.467 \\
Stockholm & -0.015 & 0.85 & -0.988 & -1.010 \\
Sydney & -0.019 & 1.48 & -0.053 & 0.386 \\
Taipei & -0.015 & 0.77 & 0.103 & 2.542 \\
Vienna & $-0.030^{*}$ & 4.51 & 0.229 & 0.776 \\
Zurich & 0.001 & 0.00 & $-0.289^{*}$ & 0.112 \\
\hline All Cities (naive) & $-0.017^{*}$ & 28.86 & $-0.190^{*}$ & 0.128 \\
\hline
\end{tabular}




\section{Table VI}

Tests of Weather-Based Trading Strategies

This table displays results of tests of the mean-variance efficiency of a global equity portfolio. The global equity portfolio return is the equal-weighted average of local currency returns of the 26 stock exchanges in the sample. Tests are performed within the framework of Britten-Jones (1999). We estimate regressions of the form

$$
1=\beta_{m} r_{m t}+\beta_{s} r_{s t}+u_{t}
$$

where $r_{m t}$ is the return on the global equity portfolio and $r_{s t}$ is the return to a weatherbased strategy on day $t$. The weather-based strategies that we consider are: the sunny strategy, in which we invest an equal amount in each exchange for which morning total sky cover $\mathrm{SKC}_{i t}^{*}$ is negative on day $t$; the cloudy strategy, in which we invest an equal amount in each exchange for which morning $\mathrm{SKC}_{i t}^{*}$ is positive on day $t$; and the sunny - cloudy strategy, in which we go long the sunny strategy and short the cloudy strategy. Morning $\mathrm{SKC}_{i t}^{*}$ is measured from 5 a.m. to 8 a.m. local time in each city on each day. A statistically significant coefficient for a return series in one of our models implies that the return series is an important component of a mean-variance portfolio. $t$-statistics are in parentheses.

\begin{tabular}{lcccc}
\hline Model & Market & Sunny & Cloudy & Sunny - Cloudy \\
\hline Model 1 & 13.53 & 13.52 & & \\
& $(2.92)$ & $(3.39)$ & & \\
Model 2 & 43.11 & & -16.16 & \\
& $(7.59)$ & & $(-3.22)$ & \\
Model 3 & 23.88 & 9.35 & -6.19 & \\
& $(1.45)$ & $(1.24)$ & $(-0.66)$ & \\
Model 4 & 27.03 & & & 7.97 \\
& $(10.72)$ & & & $(3.45)$ \\
\hline
\end{tabular}

